\title{
Constrained Agency in Later Working Lives: Introduction to the Special Issue
}

\author{
Marleen Damman ${ }^{1,2}$ and Kène Henkens ${ }^{1,2,3}$
}

\author{
1. Netherlands Interdisciplinary Demographic Institute (NIDI-KNAW), The Hague, The Netherlands \\ 2. University Medical Center Groningen, University of Groningen, Groningen, The Netherlands \\ 3. Department of Sociology and Anthropology, University of Amsterdam, Amsterdam, The Netherlands
}

\begin{abstract}
In the social sciences there is an ongoing debate about the primacy of structure or agency in shaping individual behaviors. This Special Issue presents a comprehensive set of papers on structure and agency in the area of later working lives and retirement, specifically focusing on situations where agency is constrained. The papers (a) study a diverse set of labor market situations in which individual agency is constrained, (b) focus on individual- and country-level predictors of constrained agency, and (c) provide insights regarding consequences of constrained agency in different areas of life. A broad range of country contexts are covered in the articles and rich—often longitudinal—data sources are used to advance our understanding of agency in later working lives. The current Introduction to the Special Issue elaborates on the theoretical background linking the different papers, briefly describes the different papers, and discusses directions for future research to follow from the full set of papers.
\end{abstract}

In the social sciences there is an ongoing theoretical debate about the role of structure and agency in shaping human behavior. Structure refers to external social structures that constrain (and enable) the choices that individuals make (Hitlin \& Elder, 2006), such as social policies, social norms, and individual social background. Agency refers to the notion that individuals are planful and make their own choices (Elder, 1994). They are actively creating their own lives (Settersten, 2003). Even though the importance that is ascribed to structure and agency differs across theoretical approaches, a "... general consensus coheres around the idea that individual action is circumscribed by structural constraints at the same time that structural forces fundamentally constitute the selves of individual actors" (Hitlin \& Johnson, 2015, p.1430). Individuals therefore differ in their opportunities for exercising agency. For instance, as mentioned by Hitlin and Elder (2006), “... members of privileged groups have more social opportunity to shape their lives and direct their actions than the less endowed" (p.37). In the life course perspective - a theoretical perspective that is often applied in gerontological research - this theoretical approach has been referred to as a model of agency within structure (Settersten, 2003, p.30).

The concepts of agency and structure also play an important role in research on late careers and retirement, although explicit reference to the agency-structure debate is relatively uncommon (Henkens, 2015). On the one hand, major structural reforms in retirement policies are taking place in many developed countries. Given the aging of populations and its consequences for public finances and labor markets, many countries are stimulating prolonged employment by tightening early exit provisions, and raising the statutory retirement age (OECD, 2015). For workers this means a major shift in their structural situation, as these contextual changes will affect the leeway individuals have in their decision-making on prolonged employment and retirement. On the other hand, trends towards more individual agency in terms of retirement-related decision-making have also been observed. With regard to preparation for later life, the distribution of responsibilities and risks has been changing over the past several decades. There is a shift towards less collective responsibility and more individual responsibility-and risk-to prepare well for one's life in old age (Denton et al., 2004).

This Special Issue of Work, Aging and Retirement focuses on both antecedents and consequences of situations where individual agency is constrained, specifically in the area of later working lives and retirement. The different papers are developed within the framework of a Theme-Group supported by the Netherlands Institute for Advanced Study in the Humanities and Social Sciences (NIAS-KNAW). In this Theme-Group retirement researchers from the Netherlands and other countries shared their expertise and worked both as a team and individually on retirement-related topics.

CONCEPTUALIZING CONSTRAINED AGENCY: FORCED AND INVOLUNTARY SITUATIONS

In theories on late careers and retirement, agency is often implicitly assumed. Retirement transitions are, for instance, commonly 
theorized as being the product of a rational decision-making process (Jex \& Grosch, 2013). Older individuals are assumed to be active agents, who weigh the costs and benefits of their present work situation and their expected future situation in retirement, and rationally opt for the most attractive alternative with the highest "expected value" (Feldman \& Beehr, 2011, p.197). The theoretical utility of the conceptualization of retirement as a rational decision-making process does, however, depend upon the extent to which retirement is the result of personal choice (Wang \& Shultz, 2010). Situations vary in the leeway they offer for individual agency. When there is no choice, individual cost-benefit considerations will no longer be of importance (Szinovacz \& Davey, 2005). This may, for instance, be the case if a worker is forced to retire because of economic problems of their firm. Furthermore, if there is choice, individuals may also perceive the outcome of their cost-benefit consideration as not reflecting their preferences, and may perceive their situation as involuntary. For example, if a worker retires to fulfill caregiving duties, the situation as a retiree may be perceived as involuntary (Szinovacz \& Davey, 2005). In the literature on later working lives, the idea of constrained agency has mainly been reflected in theoretical ideas about discrepancies between retirement preferences/ intentions and behavior (e.g., Henkens \& Tazelaar, 1997), as well as in the notions of forced and perceived involuntary late-career work exits (e.g., Ebbinghaus \& Radl, 2015).

The literature has shown that a considerable portion of transitions into retirement are constrained in one way or the other. By analyzing data from the Health and Retirement Study, Szinovacz and Davey (2005) have shown that about $30 \%$ of retirement transitions were perceived as involuntary in the United States. A study conducted in the Netherlands by Van Solinge and Henkens (2007) showed that about one out of four retirement transitions were not made (entirely) voluntarily. Dorn and Sousa-Poza (2010) conclude that the incidence of involuntary early retirement differs noticeably between countries. Data from the International Social Survey Program show that more than half of the retirement transitions were being perceived as involuntary in countries like Hungary, Portugal, and Germany. Ebbinghaus and Radl (2015) show in a recent study based on the European Social Survey data that for about one third of retirees, constraints to their retirement decisions could be observed. Interestingly, these authors examine both forced and perceived involuntary exits and show that there is little overlap between these two dimensions of constrained retirement (Ebbinghaus \& Radl, 2015).

Furthermore, the literature has generally displayed that constrained agency in late-career transitions negatively affects individual outcomes. Involuntary retirement transitions have been shown to have a negative impact on retirement satisfaction (Shultz, Morton, \& Weckerle, 1998; Van Solinge \& Henkens, 2008), life satisfaction (Calvo, Haverstick, \& Sass, 2009; De Vaus et al., 2007; Dingemans \& Henkens, 2014; Hershey \& Henkens, 2014), self-efficacy (Dingemans \& Henkens, 2015), perceived health (van Solinge, 2007), and healthy lifestyle indicators (Henkens, Van Solinge, \& Gallo, 2008). Also when not solely focusing on retirement transitions, but on involuntary employment exits in later life more generally, negative effects for individuals' mental health, physical health, and lifestyle have been observed (Gallo et al., 2000; Gallo et al., 2001; Hyde et al., 2015). On the whole, limited choice and control over one's late-career employment exit seems to negatively impact the well-being of older individuals (Barbosa, Monteiro, \& Murta, 2016).
CONTRIBUTIONS OF THE SPECIAL ISSUE

In this Special Issue we propose several directions for conceptual and theoretical advancement of the literature about constrained agency in the context of later working lives and retirement. These directions are developed in more detail in the different papers of the Special Issue. We briefly describe these topics below.

First, this Special Issue presents papers on a diverse set of labor market situations in which individual agency is constrained. Especially in a context of population aging, prolonged working lives, and labor market flexibilization, a forced or involuntary situation may be reflected not only by late-career labor market exit, but also by continued employment (e.g., Fisher et al., 2016) and the type of employment (employee vs. self-employed; e.g., Halvorsen \& Morrow-Howell, 2016). As noted by Ebbinghaus and Radl (2015), given the trend towards higher retirement ages and a shift towards more privately funded pensions, the topic of involuntary postponement of retirement increases in importance. They argue that "... in the future the main form of involuntariness in retirement might consist in being forced to continue to work longer than one would have wished" (Ebbinghaus \& Radl, 2015, p.126). Furthermore, in light of the trend towards increasingly flexible labor markets (Conen, Schippers, \& Schulze Buschoff, 2016; Kösters \& Souren, 2014), the notion that a considerable portion of self-employed are involuntarily pushed into this employment state warrants attention (Kautonen et al., 2010). Poschke (2013) shows on the basis of the Global Entrepreneurship Monitor that the percentage of entrepreneurs out of necessity is $21 \%$ in OECD countries. These different dimensions of constrained agency-in terms of employment exit, continued employment, and type of employment-all receive attention in this Special Issue.

Second, this Special Issue covers antecedents of (perceived) limited agency. Here the central question is: Which individuals are being constrained in their agency during later working lives and retirement processes? Attention is paid to both individual-level predictors of constrained agency (e.g., educational level) and the explanatory role that macro-level factors play (e.g., employment protection legislation in different countries). Third, consequences of (perceived) limited agency for a variety of outcomes are examined in this Special Issue. Whereas much earlier research on the implications of constrained agency in late-career transitions has focused on mental and physical well-being, this scope of outcomes is broadened in this Special Issue, for instance by focusing on financial preparation for retirement, later-life income, and emotions.

\section{OVERVIEW OF THE SPECIAL ISSUE}

The first article of this Special Issue focuses on predictors of limited agency during later working lives. Hyde and Dingemans (2017) examine the incidence and predictors of forced career exit, among individuals aged 50 to 80 years, in a broad range of European countries. By analyzing four waves of data of the Survey of Health, Ageing and Retirement in Europe (SHARE) of 13 European countries, the authors show that many older workers are still forced out of employment, even though policies are increasingly focused on prolonging working lives. The proportions of forced career exits ranged between 20\% in Sweden to about 50\% in Estonia. In line with the expectations, career exits via the retirement route were found to be less likely to have been forced as compared to career exits via non-retirement routes (i.e., 
unemployment and disability). Furthermore, the analyses show that in countries with a higher level of employment protection legislation, the likelihood of forced career exit via retirement is higher than in countries with a lower employment protection legislation level. These findings suggest that in countries where older workers are relatively well-protected on the labor market, retirement may become a pathway to lay off older individuals. Overall, the paper makes an important contribution to the scientific literature and societal discussions on latecareer exits, by examining the interaction between macro-level and micro-level structural factors, and by raising awareness of the issue on "hidden unemployment in later life."

The subsequent two papers of this Special Issue-although they differ considerably in their focus and approach-both examine the consequences of limited agency on the labor market for individuals' financial resources. More specifically, in the second paper of the Special Issue, Hershey and colleagues (2017) compare financial savings and perceived future pension adequacy of individuals who are voluntarily self-employed, with those who are forced into self-employment. The study, which is conducted among self-employed workers aged 15-65 in Germany and the Netherlands, shows that about one out of four solo self-employed individuals was forced into this employment state out of necessity. These forced solo self-employed individuals appear to be less financially prepared for retirement than their voluntarily selfemployed counterparts. Furthermore, the analyses show the importance of psychological factors, such as financial knowledge, retirement goal clarity, and future time perspective for understanding differences in financial preparation for retirement among the solo self-employed. The study contributes significantly to our understanding of the financial preparation for retirement of the solo self-employed, and emphasizes the relative vulnerability of forced solo self-employed individuals, both on the labor market and in terms of their financial prospects for old age.

In the third paper, Heisig and Radl (2017) examine the impact of late-career job loss-a clear indicator of limited agency in terms of job exit-on late-career labor supply and later-life income. By analyzing 30 years of data of the German Socioeconomic Panel, following individuals who lose their jobs (between the ages 50 and 64 years) for up to 10 years after job loss, and comparing them with a compositionadjusted control group, the authors provide a comprehensive picture of the long-term implications of later-life involuntary job loss. The findings show that after late-career job loss, many older workers do not return into a paid job. Also the financial implications are severe, especially for those who experience the job loss in their early fifties. For this group, a clear disadvantage in terms of yearly income continues to exist until 10 years after involuntary job loss, which suggests the existence of a so-called scarring effect. Overall, the results of the study point at the economic vulnerability of individuals who involuntarily lost their jobs due to dismissal or firm closure during late careers. This finding especially warrants attention in a context in which early exit routes are being closed and individuals are encouraged to prolong employment.

The fourth article focuses on the other dimension of the late-career employment spectrum: continued employment in a context in which important policy reforms have taken place to prolong working lives. Using data from the first wave of the NIDI Pension Panel Study, Van Solinge and Henkens (2017) examine the emotional reactions-anger about the retirement reforms and worry about individual capabilities to continue working until the higher retirement age-of workers aged 60 and over in the Netherlands. Even though the macro-level reforms apply to all workers, and generally constrain opportunities for agency regarding retirement timing, the authors argue that emotional responses to the policy reforms may differ between individuals due to differential access to resources (e.g., health, wealth, and partner support). Even within a constraining context, access to individual resources such as wealth may still offer opportunities for agency, and may therefore relate to less anger and worry. The data show that anger and worry are widespread among the studied workers. About $45 \%$ of the study participants are very angry about the later retirement age, and $40 \%$ are very worried about whether they can physically keep up. In line with the hypotheses, the study shows that negative emotions are generally weaker among workers having more access to resources. The study emphasizes that for more vulnerable groups - the less educated, less healthy older workers with lower social status-the retirement reforms have a severe negative impact on their emotional states.

Paper five of the Special Issue focuses on the preretirement years as well. The authors examine in the Australian context-where older individuals are assumed to be flexible in their retirement timing decisions - whether there is a dynamic effect of a change in job satisfaction on subsequent change in retirement intentions. By following a group of older workers over a 1-year period by means of three surveys, Zacher and Rudolph (2017) show that a change in job satisfaction negatively predicts a change in retirement intentions. An increase in job satisfaction over 6 months of time was found to lead to a decline in retirement intentions over the following 6 months. A reverse causal effect of changes in retirement intentions on changes in job satisfaction was ruled out by the statistical technique used in the study. These findings highlight the importance for organizations to monitor the job satisfaction of their older employees well.

The final article of this Special Issue focuses on the postretirement period. In the article Von Bonsdorff, Zhan, Song, and Wang (2017) examine predictors of decisions to transition into full retirement, bridge employment in self-employment, and bridge employment in wageand-salary employment. Moreover, given that the retirement processes of entrepreneurs are understudied, attention is paid to preretirement employment form (entrepreneur vs. wage-and-salary employee) as well. Analyses are based on the longitudinal Health and Retirement Study data from the United States. The findings show that there generally is continuity in terms of employment form across the retirement transition. Preretirement self-employed individuals are more likely to work in self-employment after retirement as compared to preretirement wageand-salary workers. Older individuals who are male, highly educated, and have had a high income, are more likely to work as self-employed after retirement as well (rather than wage-and-salary bridge employment), suggesting that access to resources is crucial for becoming a selfemployed bridge worker. The findings make an important contribution to the bridge employment literature by showing that self-employment is an independent form of bridge employment, which seems to be more common among the higher socioeconomic strata.

\section{CONCLUSION AND FUTURE DIRECTIONS}

This Special Issue provides a comprehensive set of papers related to the agency-structure debate in research on later working lives and retirement. The papers capture a diverse set of labor market situations in which individual agency is constrained, focus on different phases of the retirement process, cover a broad range of country contexts, and use 
rich—often longitudinal—data sources to advance our understanding of antecedents and consequences of constrained agency in later working lives.

The first general impression that emerges from the set of papers is that constrained agency has negative-potentially enduring-implications for individuals. In terms of financial consequences, both the study by Hershey and colleagues (2017) and the study by Heisig and Radl (2017) show that limited agency on the labor market negatively impacts the financial situation of individuals, and suggest that constrained labor market agency may have long-term implications for individual financial well-being. These findings highlight that for understanding later working lives and retirement transitions, it is not only relevant to examine the role of situations of limited agency in the years around retirement, but to pay attention to mid-life and even to the years before that as well (cf. the life course proposition of lifelong development; e.g., Damman, Henkens, \& Kalmijn, 2011; Raymo, Warren, Sweeney, Hauser, \& Ho, 2011; Settersten, 2003).

The second general impression based on this set of papers is that opportunities for exercising agency are unequally distributed between socioeconomic groups. Both the paper by Hyde and Dingemans (2017) and the paper by Heisig and Radl (2017) show that educational level is negatively associated with involuntary or forced job loss. Less educated workers carry a higher risk of experiencing an involuntary-too early-employment exit during their late careers as compared to their higher-educated counterparts. Among those who continue working until older ages, however, older workers with a lower socioeconomic background also experience most adjustment problems to higher retirement ages, as the study by Van Solinge and Henkens (2017) shows. Paying attention to these vulnerable groups on the labor market in employment and retirement policies is therefore highly important.

In the current Special Issue the focus has mainly been on opportunities for exercising agency and between-individual differences in this respect. Several of the papers suggest, for instance, that financial resources are giving individuals more opportunities to shape their lives. In the broader sociological life course literature on the agencystructure debate, increasing attention is being paid to more directly conceptualizing and measuring the notion of life course agency. In these studies agency refers to the "ability to formulate and pursue life plans" (Hitlin \& Elder, 2007, p.183), or “actors' proactive capacities" (Hitlin \& Johnson, 2015, p.1436). Empirical indicators of life course agency are, for instance, planful competence (Clausen, 1991), self-efficacy (Hitlin \& Elder, 2006), and mastery (Hitlin \& Johnson, 2015), and the debate about how it can more accurately be measured is still going on. An important step for future research on the role of structure and agency in shaping later working lives would be to integrate the focus on opportunities for agency, with the notion of agentic capacities, and to examine in which contexts agentic capacities matter and in which they are of less importance.

For doing this, theories on "situational strength" may provide important ideas. In these theories it is argued that situations differ in terms of their situational strength, which has been defined as "... implicit or explicit cues provided by external entities regarding the desirability of potential behaviors" (Meyer, Dalal, \& Hermida, 2010, p.122). Strong situational contexts might constrain the expression of between-individual differences. Weak situational contexts might rather provide opportunities for the expression of between-individual differences. The general hypothesis is that between-individual differences such as personality are least important for explaining behavior in strong situations, and are most important in weak situations (Cooper $\&$ Withey, 2009). The theory thus focuses on how situations moderate the relationships between individual differences and outcome behaviors. An example of a strong contextual situation in the retirement field is when individuals are automatically enrolled in pension saving schemes. In such a situation, the impact of agentic capacities on saving behaviors may be relatively low, whereas in a context where individuals carry the full responsibility for retirement savings themselves, agentic capacities may have a strong impact on saving behaviors.

The notions of structure and agency are highly relevant in the context of later working lives and retirement. Explicit reference to the agency-structure debate is relatively uncommon in retirement research. Many studies do, however, implicitly incorporate the notions of agency and structure in theoretical reasoning or empirical modeling. This Special Issue aimed to contribute to our understanding of the role of structure and agency in the context of later working lives, by presenting a comprehensive set of papers on both antecedents and consequences of limited agency, and by discussing potential directions for future research. By means of this Special Issue we hope to raise awareness of the centrality of the concepts of structure and agency in retirement theorizing and empirical work, and emphasize the importance of crossing interdisciplinary boundaries (i.e., sociologists often examining structural factors/ psychologists examining indicators of human agency) in retirement research.

\section{ACKNOWLEDGMENTS}

This work was supported by the Netherlands Organization for Scientific Research NWO (VICI Grant 453-14-001 to K. Henkens), and by the Netherlands Institute for Advanced Study in the Humanities and Social Sciences (NIAS-KNAW).

\section{REFERENCES}

Barbosa, L. M., Monteiro, B., \& Murta, S. G. (2016). Retirement adjustment predictors-a systematic review. Work, Aging and Retirement, 2, 262-280. doi:10.1093/workar/waw008

Calvo, E., Haverstick, K., \& Sass, S. A. (2009). Gradual retirement, sense of control, and retirees' happiness. Research on Aging, 31, 112-135. doi:10.1177/0164027508324704

Clausen, J. S. (1991). Adolescent competence and the shaping of the life course. American Journal of Sociology, 96, 805-842. doi: 10.1086/229609

Conen, W., Schippers, J., \& Schulze Buschoff, K. (2016). Self-employed without personnel. Between freedom and insecurity. Düsseldorf, Germany: WSI der Hans-Böckler-Stiftung.

Cooper, W. H., \& Withey, M. J. (2009). The strong situation hypothesis. Personality and Social Psychology Review, 13, 62-72. doi: $10.1177 / 1088868308329378$

Damman, M., Henkens, K., \& Kalmijn, M. (2011). The impact of midlife educational, work, health, and family experiences on men's early retirement. The Journals of Gerontology Series B: Psychological Sciences and Social Sciences, 66, 617-627. doi:10.1093/geronb/ gbr092

De Vaus, D., Wells, Y., Kendig, H., \& Quine, S. (2007). Does gradual retirement have better outcomes than abrupt retirement? Results 
from an Australian panel study. Ageing \& Society, 27, 667-682. doi:10.1017/S0144686X07006228

Denton, M. A., Kemp, C. L., French, S., Gafni, A., Joshi, A., Rosenthal, C. J., \& Davies, S. (2004). Reflexive planning for later life. Canadian Journal on Aging Supplement, 23, S71-S82. doi:10.1353/ cja.2005.0031

Dingemans, E., \& Henkens, K. (2014). Involuntary retirement, bridge employment, and satisfaction with life: A longitudinal investigation. Journal of Organizational Behavior, 35, 575-591. doi:10.1002/ job.1914

Dingemans, E., \& Henkens, K. (2015). How do retirement dynamics influence mental well-being in later life? A 10-year panel study. Scandinavian Journal of Work, Environment \& Health, 41, 16-23. doi:10.5271/sjweh.3464

Dorn, D., \& Sousa-Poza, A. (2010). "Voluntary" and "involuntary" early retirement: An international analysis. Applied Economics, 42, 427-438. doi:10.1080/00036840701663277

Ebbinghaus, B., \& Radl,J. (2015). Pushed out prematurely? Comparing objectively forced exits and subjective assessments of involuntary retirement across Europe. Research in Social Stratification and Mobility, 41, 115-130. doi:10.1016/j.rssm.2015.04.001

Elder, G. H. (1994). Time, human agency, and social change: Perspectives on the life course. Social Psychology Quarterly, 57, 4-15. doi: $10.2307 / 2786971$

Feldman, D. C., \& Beehr, T. A. (2011). A three-phase model of retirement. American Psychologist, 66, 193-203. doi:10.1037/a0022153

Fisher, G. G., Ryan, L. H., Sonnega, A., \& Naudé, M. N. (2016). Job lock, work, and psychological well-being in the united states. Work, Aging and Retirement, 2, 345-358. doi:10.1093/workar/waw004

Gallo, W. T., Bradley, E. H., Siegel, M., \& Kasl, S. (2000). Health effects of involuntary job loss among older workers: Findings from the health and retirement survey. Journal of Gerontology: Social Sciences, 55B, S131-S140. doi:10.1093/geronb/55.3.S131

Gallo, W. T., Bradley, E. H., Siegel, M., \& Kasl, S. V. (2001). The impact of involuntary job loss on subsequent alcohol consumption by older workers: Findings from the health and retirement survey. Journal of Gerontology: Social Science, 56B, S3-S9. doi:10.1093/geronb/56.1.S3

Halvorsen, C. J., \& Morrow-Howell, N. (2016). A conceptual framework on self-employment in later life: Toward a research agenda. Work, Aging and Retirement. Advance online publication. doi:10.1093/workar/waw031

Heisig, J. P., \& Radl, J. (2017). Adding scars to wrinkles? Long-run effects of late-career job loss on retirement behavior and personal income. Work, Aging and Retirement, 3, 257-272. doi:10.1093/ workar/wax006

Henkens, K. (2015). Labor force transitions in late life: Between agency and structure. In L. Finkelstein, D. Truxillo, F. Fraccaroli \& R. Kanfer (Eds.), Facing the challenges of a multi-age workforce: A use-inspired approach (pp. 321-330). London: Routledge.

Henkens, K., \& Tazelaar, F. (1997). Explaining retirement decisions of civil servants in the Netherlands. Research on Aging, 19, 139-173. doi: $10.1177 / 0164027597192001$

Henkens, K., Van Solinge, H., \& Gallo, W. T. (2008). Effects of retirement voluntariness on changes in smoking, drinking and physical activity among Dutch older workers. European Journal of Public Health, 18, 644-649. doi:10.1093/eurpub/ckn095
Hershey, D. A., \& Henkens, K. (2014). Impact of different types of retirement transitions on perceived satisfaction with life. The Gerontologist, 54, 232-244. doi:10.1093/geront/gnt006

Hershey, D. A., Van Dalen, H. P., Conen, W., \& Henkens, K. (2017). Are 'voluntary' self-employed better prepared for retirement than 'forced' self-employed? Work, Aging and Retirement, 3, 243-256. doi:10.1093/workar/wax008

Hitlin, S., \& Elder, G. H. (2006). Agency: An empirical model of an abstract concept. Advances in Life Course Research, 11, 33-67. doi:10.1016/S1040-2608(06)11002-3

Hitlin, S., \& Elder, G. H. (2007). Time, self, and the curiously abstract concept of agency. Sociological Theory, 25, 170-191. doi:10.1111/j.1467-9558.2007.00303.x

Hitlin, S., \& Johnson, M. K. (2015). Reconceptualizing agency within the life course: The power of looking ahead. American Journal of Sociology, 120, 1429-1472. doi:10.1086/681216

Hyde, M., \& Dingemans, E. (2017). Hidden in plain sight? Does stricter employment protection legislation lead to an increased risk of hidden unemployment in later life. Work, Aging and Retirement, 3, 231-242. doi:10.1093/workar/wax013.

Hyde, M., Hanson, L. M., Chungkham, H. S., Leineweber, C., \& Westerlund, H. (2015). The impact of involuntary exit from employment in later life on the risk of major depression and being prescribed anti-depressant medication. Aging \& Mental Health, 19, 381-389. doi:10.1080/13607863.2014.927821

Jex, S. M., \& Grosch, J. (2013). Retirement decision making. In M. Wang (Ed.), The oxford handbook of retirement (pp. 267-279). New York: Oxford University Press.

Kautonen, T., Down, S., Welter, F., Vainio, P., Palmroos, J., Althoff, K., \& Kolb, S. (2010). "Involuntary self-employment" as a public policy issue: A cross-country european review. International Journal of Entrepreneurial Behaviour \& Research, 16, 112-129. doi:10.1108/13552551011027002

Kösters, L., \& Souren, M. (2014). De toename van zzp'ers in europees perspectief [the increase of solo self-employment in a European perspective]. Economisch-Statistische Berichten (ESB), 99, 247-249.

Meyer, R. D., Dalal, R. S., \& Hermida, R. (2010). A review and synthesis of situational strength in the organizational sciences. Journal of Management, 36, 121-140. doi:10.1177/0149206309349309

OECD. (2015). Pensions at a glance 2015. OECD and G20 indicators. Paris: Organisation of Economic Co-operation and Development.

Poschke, M. (2013). Entrepreneurs out of necessity: A snapshot. Applied Economics Letters, 20, 658-663. doi:10.1080/13504851.2 012.727968

Raymo, J. M., Warren, J. R., Sweeney, M. M., Hauser, R. M., \& Ho, J.H. (2011). Precarious employment, bad jobs, labor unions, and early retirement. The Journals of Gerontology Series B: Psychological Sciences and Social Sciences, 66B, 249-259. doi:10.1093/geronb/ gbq106

Settersten, R. A. (2003). Propositions and controversies in life-course scholarship. In R. A. Settersten (Ed.), Invitation to the life course. Towards new understandings of later life (pp. 15-48). New York: Baywood.

Shultz, K. S., Morton, K. R., \& Weckerle, J. R. (1998). The influence of push and pull factors on voluntary and involuntary early retirees' 
retirement decision and adjustment. Journal of Vocational Behavior, 53, 45-57. doi:10.1006/jvbe.1997.1610

Szinovacz, M. E., \& Davey, A. (2005). Predictors of perceptions of involuntary retirement. The Gerontologist, 45, 36-47. doi:10.1093/ geront/45.1.36

Van Solinge, H. (2007). Health change in retirement - a longitudinal study among older workers in the Netherlands. Research on Aging, 29, 225-256. doi:10.1177/0164027506298223

Van Solinge, H., \& Henkens, K. (2007). Involuntary retirement: The role of restrictive circumstances, timing, and social embeddedness. Journals of Gerontology Series B-Psychological Sciences and Social Sciences, 62, S295-S303. doi:10.1093/geronb/62.5.S295

Van Solinge, H., \& Henkens, K. (2008). Adjustment to and satisfaction with retirement: Two of a kind? Psychology and Aging, 23, 422-434. doi: 10.1037/0882-7974.23.2.422
Van Solinge, H., \& Henkens, K. (2017). Older workers' emotional reactions to rising retirement age: The case of the Netherlands. Work, Aging and Retirement, 3, 273-283. doi:10.1093/workar/ wax010

Von Bonsdorff, M., Zhan, Y., Song, Y., \& Wang, M. (2017). Examining bridge employment from a self-employment perspective - evidence from the health and retirement study. Work, Aging and Retirement, 3, 298-312. doi:10.1093/workar/ wax012.

Wang, M., \& Shultz, K. S. (2010). Employee retirement: A review and recommendations for future investigation. Journal of Management, 36, 172-206. doi:10.1177/0149206309347957

Zacher, H., \& Rudolph, C. W. (2017). Change in job satisfaction negatively predicts change in retirement intentions. Work, Aging and Retirement, 3, 284-297. doi:10.1093/workar/wax009 